\title{
Differences in Transmitter Release and Number of Nerve Terminals per Motoneuron Between Two Frog Muscles
}

\author{
Y.-M. M. Yao and J. N. Weakly' \\ Department of Physiology and The Neurobiology Program, School of Medicine, University of North Carolina at \\ Chapel Hill, Chapel Hill, North Carolina 27514
}

Recent studies suggest that the number of nerve terminals maintained per motoneuron and perhaps other motoneuron properties (Grinnell and Herrera, 1980a; Grinnell and Trussell, 1983) influence transmitter release. We have examined, in detail, the structure and function of motoneurons innervating two different twitch muscles, the sartorius and the ext. long. dig. IV (e.l.d.) in the adult frog using histochemical and electrophysiological techniques. These studies were undertaken with a view towards learning whether differences in the number of nerve terminals per motoneuron were correlated with differences in transmitter release between motoneurons innervating these two muscles. Moreover, these studies provide detailed, quantitative data that are a necessary prerequisite for carrying out additional studies to examine the possible influence of muscle on transmitter release properties.

In low $\mathrm{Ca}^{2+}$-high $\mathrm{Mg}^{2+}$ Ringer's solution, mean quantal content $(m)$ and miniature end-plate potential (MEPP) frequency were larger at sartorius than at e.l.d. end-plates. The mean length of nerve terminals was also found to be greater in sartorius than in e.l.d. muscles. When release was normalized for the difference in terminal length, $m$ remained larger in the sartorius, whereas MEPP frequency in the two muscles was similar. Cell bodies of individual sartorius motoneurons were greater in crosssectional area and maintained approximately 5.6-fold greater aggregate length of nerve terminals per motoneuron than did e.l.d. motoneurons. This greater aggregate length of nerve terminal contact with their respective target muscles is primarily a result of a greater number of nerve terminals supported by sartorius than by e.l.d. motoneurons. Total spontaneous (MEPP frequency) and evoked $(m)$ quantal release were 5.5 and $11.4 \times$ greater, respectively, from individual sartorius motoneurons than from e.l.d. motoneurons. The results of this study are discussed in terms of the relationship between transmitter release and the number of nerve terminals maintained per motoneuron.

There are marked differences in synaptic efficacy among junctions within the same muscle as well as between junctions in different muscles in the frog. A number of studies have shown that transmitter release from frog motor nerve terminals is positively correlated with end-plate size, which, in turn, is correlated with muscle fiber diameter (Angaut-Petit and Mallart, 1979; Grinnell and Herrera, 1980b; Kuno et al,, 1971; Nudell and Grinnell, 1982). In addition, transmitter release and end-plate

\footnotetext{
Received Jan. 29, 1985; revised May 8, 1985; accepted June 4, 1985.
}

We thank T. W. Bouldin and C. Metz for assistance with some of the histological material, and E. A. Connor, M. Kuno, U. J. McMahan, and P. B. Sargent for reading of the manuscript.

Correspondence should be addressed to Dr. Yao at Department of Neurobiology, Stanford University School of Medicine, Stanford, CA 94305

i Present address: Department of Clinical Research, Burroughs Wellcome Co., Research Triangle Park, NC 27709.

Copyright (C) 1986 Society for Ncuroscience $0270-6474 / 86 / 020498-09 \$ 02.00 / 0$ length tend to be more uniform at junctions along the same fiber than between different fibers in multiply innervated muscles (Nudell and Grinnell, 1983; Weakly, 1978). Together these findings provide evidence suggestive that the muscle fiber may play a role in synaptic growth and function.

The overall relationship between transmitter release per endplate and muscle fiber diameter shows considerable variability. For example, end-plates of comparable length may be associated with 10 - to 20 -fold differences in $m$ value (Kuno et al., 1971; Nudell and Grinnell, 1982). Moreover, subgroups of muscle fibers having similar diameters show a correlation between release and fiber diameter that is actually the inverse of that seen in the population of end-plates and muscle fibers as a whole (Nudell and Grinnell, 1982). That transmitter release may vary independently of muscle fiber diameter suggests that release may depend, at least in part, on intrinsic properties of the motoneurons.

One possible determinant of transmitter release at individual synapses is the total number of terminals maintained by the motoneuron. For example, a given motoneuron may produce predetermined amounts of material required for the synthesis of transmitter, so that the amount delivered to a given nerve terminal is influenced by the number of nerve terminals supported by the motoneuron. However, in experiments that might bear on this point, direct determination of the number of motoneurons and the total number of nerve terminals innervating a given muscle has not been made. Thus, the results have led to apparently disparate conclusions: In some model systems, release and number of terminals per motoneuron are inversely related (Grinnell and Herrera, 1980b; Herrera and Grinnell, 1980; Pockett and Slack, 1982; Slack and Hopkins, 1982); in others, a positive correlation has been reported (Grinnell and Herrera, 1980a; Grinnell and Trussell, 1983).

The present study was undertaken to examine the extent to which transmitter release is correlated with the number of nerve terminals maintained by the motoneurons innervating two twitch muscles, e.l.d. and the sartorius, in the frog hindlimb. By use of retrograde labeling with HRP, the number of motoneurons supplying each muscle was determined, and the average number of terminals per motoneuron was calculated. We find significant differences in transmitter release, both at the level of individual terminals and from the sum total of nerve terminals between sartorius and e.l.d. motoneurons.

\section{Materials and Methods}

Experiments were performed on excised sartorius and e.l.d. nerve-muscle preparations from Rana pipiens $(7.0-8.0 \mathrm{~cm}$ in body length; purchased from Carolina Biological Supply Co.). Muscles were pinned out at $1.1 \times$ their in situ resting length in a Sylgard-lined bath. All experiments were performed at room temperature $\left(20-22^{\circ} \mathrm{C}\right)$, and unless otherwise specified (see below), preparations were bathed in Ringer's solution of the following composition: $\mathrm{NaCl}, 106.0 \mathrm{~mm} ; \mathrm{KCl}, 2.0 \mathrm{~mm}$, $\mathrm{CaCl}_{2}, 1.8 \mathrm{~mm}$; Tris IIC1, $10.0 \mathrm{~mm}$ (pII 7.2). 
Table 1. Physiological and morphological properties of end-plates, muscle fibers, and motoneurons for frog sartorius and e.l.d. muscles ${ }^{a}$

$\begin{array}{lll}\text { Parameter } & \begin{array}{l}\text { Sartorius } \\ \text { muscle }\end{array} & \begin{array}{l}\text { E.1.d. } \\ \text { muscle }\end{array}\end{array}$

a. Number of extrafusal muscle fibers

b. Diameter $(\mu \mathrm{m})$ of extrafusal muscle fibers

c. Input resistance $(\mathrm{M} \Omega)$ of extrafusal muscle fibers

d. \% End-plates with focal polyneuronal innervation

e. Number of end-plates per fiber

f. Number of motoneurons

g. Cross-sectional area $\left(\mu \mathrm{m}^{-2}\right)$, motoneuron cell body

h. End-plate (total nerve terminal) length $(\mu \mathrm{m})$

i. $m$ per end-plate

j. $\quad m$ per unit length $\left(1000 \mu \mathrm{m}^{-1}\right)$ of nerve terminal

k. MEPP frequency $\left(\mathrm{sec}^{-1}\right)$ per end-plate

1. MEPP frequency per unit length $\left(1000 \mu \mathrm{m}^{-1}\right)$ of nerve terminal

$$
\begin{array}{rr}
804.0 \pm 27.7 & 78.4 \pm 2.4^{b} \\
(n=5) & (n=13) \\
58.0 \pm 4.0 & 39.4 \pm 3.9^{b} \\
(n=14) & (n=13) \\
0.7 \pm 0.1 & 1.1 \pm 0.1^{b} \\
(n=22) & (n=22) \\
7.1 \pm 0.8 & 1.0 \pm 0.6^{b} \\
(n=14) & (n=11) \\
2.7 \pm 0.2 & 1.3 \pm 0.1^{b} \\
(n=11) & (n=11) \\
16.5 \pm 0.9 & 3.2 \pm 0.5^{b} \\
(n=7) & (n=6) \\
1601.7 \pm 49.8 & 1113.3 \pm 67.9^{b} \\
(n=10) & (n=10) \\
1002.6 \pm 113.9 & 740.4 \pm 82.1^{b} \\
(n=14) & (n=13) \\
3.6 \pm 0.7 & 1.3 \pm 0.2^{b} \\
(n=22) & (n=22) \\
3.7 \pm 0.9 & 1.7 \pm 0.3^{b} \\
(n=14) & (n=13) \\
1.1 \pm 0.2 & 0.8 \pm 0.1^{b} \\
(n=22) & (n=22) \\
1.1 \pm 0.3 & 1.2 \pm 0.2^{b} \\
(n=14) & (n=13)
\end{array}
$$

$n$ refers to number of animals in the experimental group.

${ }^{a}$ Values are mean \pm SEM.

${ }^{b}$ Normal sartorius and e.l.d. values statistically different $(p<0.05)$ by two-tailed $t$ test.

\section{Electrophysiology}

Intracellular recordings of resting and end-plate potentials (EPP) were made from superficial muscle fibers impaled with glass microelectrodes filled with $2 \mathrm{M}$ potassium acetate $(8-10 \mathrm{M} \Omega$ ). Input resistance was determined using electrodes for current injection and potential recording inserted into the same fiber at less than $50 \mu \mathrm{m}$ separation. The e.l.d. muscle contains a small population $(<10 \%)$ of slow fibers (Gray, 1958); care was taken in all recordings from the e.l.d. muscle to ensure that data were collected only from twitch muscle fibers. End-plate responses in twitch fibers were identified by the criteria of sharp localization, short latency, and low threshold to nerve stimulation (Kuffler and Vaughan Williams, 1953).

Modified amphibian Ringer's solution containing $0.6 \mathrm{mM} \mathrm{CaCl}_{2}$ and $10.0 \mathrm{mM} \mathrm{MgCl}{ }_{2}$ was used for measurement of mean quantal content ( $m$ value) and miniature end-plate potential (MEPP) amplitude and frequency. Neostigmine methylsulfate $\left(10^{-6} \mathrm{gm} / \mathrm{ml}\right)$ was added to increase the amplitude of MEPPs. For each junction, 50-200 EPPs were recorded while stimulating the nerve with a suction electrode at a frequency of $0.5 / \mathrm{sec}$. This procedure was followed by recording a series of $50-100$ MEPPs. Recordings of EPPs and MEPPs were made at a minimum of 10 end-plates (range, 10-23) in each muscle. Results were accepted only from those fibers in which the resting potential fell less than $10 \mathrm{mV}$ during the entire recording period and whose final value was not less than $-80 \mathrm{mV}$.

Mean quantal content $(m)$ was calculated by three methods (Del Castillo and Katz, 1954): (1) From the ratio of the mean EPP amplitude to the mean MEPP amplitude ( $m=$ EPP/MEPP), (2) from the method of failures ( $m=\ln$ (no. trials/no. failures)), and (3) from the coefficient of variation (CV) of the EPP amplitude distribution $\left(m=1 / \mathrm{CV}^{2}\right)$. The three $m$ values were averaged, and the results from a junction were discarded unless the individual $m$ values agreed closely (within $15 \%$ ) with the averaged $m$ value. In the present study, individual EPP amplitudes were not greater than $15 \%$ of the resting potential; therefore, no correction for nonlinear summation was required (McLachlan and Martin, 1981).

For each of 27 muscles (14 sartorius, 13 e.l.d.) in which combined electrophysiological and morphological data were obtained, values of $m$ and MEPP frequency per unit length of nerve terminal were calculated from the ratio of the mean value of $m$ or mean frequency and the mean terminal length for that muscle. Terminal length was determined (see below) from junctions on randomly selected, superficial muscle fibers following completion of the electrophysiological portion of the experiments. The values of $m$ and MEPP frequency per unit length shown in Table 1 represent averages of the values in these 27 muscles.

For determination of the incidence of focal polyneuronal innervation, muscles werc bathed in normal Ringer's containing curarc $(2.0-3.5 \times$ $\left.10^{-6} \mathrm{M}\right)$. Polyneuronally innervated junctions were identified by the presence of "step" changes in the EPP amplitude with gradations in the intensity and/or duration of stimuli applied to the nerve (Redfern, 1970). Approximately 50 (range, 40-100) sartorius and 25 (range, 10-35) e.l.d. junctions were examined in each muscle.

\section{Histology}

Nerve terminals were stained with nitroblue tetrazolium (NBT; Letinsky and DeCino, 1980), and muscle end-plates were stained for AChE activity (Karnovsky and Roots, 1964). Muscles were prefixed while in place in the recording chamber with $2.5 \%$ glutaraldehyde- $10 \%$ dimethyl sulfoxide (DMSO) in $0.1 \mathrm{M}$ phosphate buffer, $\mathrm{pH}$ 7.3. After a brief prefix, the nerve terminals were stained for $4-6 \mathrm{~min}$ with NBT $(1.0 \mathrm{mg} / \mathrm{ml}$; Sigma) and phenazine methylsuftatc $(0.1 \mathrm{mg} / \mathrm{ml}$; Sigma), freshly prepared in $2.5 \%$ glutaraldehyde-10\% DMSO and phosphate buffer solu- 


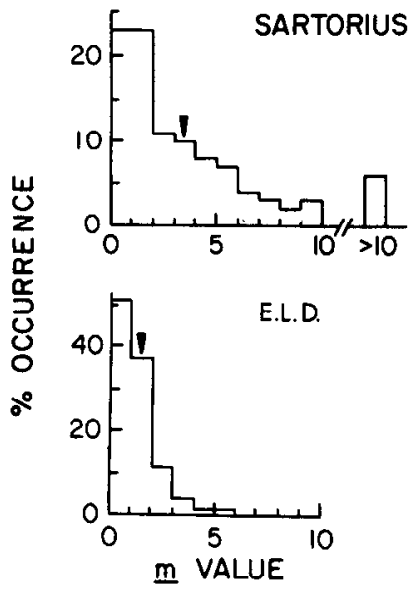

Figure 1. Histograms showing distribution of $m$ values for EPPs at sartorius and e.1.d. end-plates. Arrows indicate means: sartorius, $3.6 \pm$ 0.7 (216 end-plates in 22 muscles); e.l.d., $1.3 \pm 0.2$ (190 end-plates in 22 muscles). Mean $m$ values for the two muscles were significantly different by $t$ test $(p<0.05)$.

tion. After rinsing in phosphate buffer for $10 \mathrm{~min}$, muscles were stained for AChE, postfixed in $2.5 \%$ glutaraldehyde, rinsed, and then stored overnight in glycerol at $4^{\circ} \mathrm{C}$.

Between 15 and 25 muscle fibers were dissected from each preparation. Following determination of the number of end-plates per muscle fiber, segments of fibers containing end-plates were dissected, and the fiber diameter (maximum diameter + minimum diameter/2) was determined using an ocular micrometer. The fiber segments were then mounted, with the end-plates en face, between coverslips in a watersoluble medium (Hydramount, Gurr) and photographed on color transparency film (Kodak Ektachrome 64) at 100-400 x under the LM. The color slides were projected onto a digital data tablet, and the total endplate length and nerve terminal length (summed length of AChE-stained regions and NBT-stained strands, respectively) were measured with the aid of a PDP-11/45 computer.

The number of muscle fibers per muscle was determined from $5 \mu \mathrm{m}$ cross sections (stained with $\mathrm{H} \& \mathrm{E}$ ) through the midportion of muscles fixed in $10 \%$ formalin.

The number of motoneurons supplying the muscles was determined using retrograde transport of HRP (Sigma, type VI). The sartorius (10 animals) or e.1.d. ( 10 animals) nerve was crushed at the muscle entry zone between the tips of \#5 watchmaker's forceps onto which HRP had been recrystallized (Farel and Bemelmans, 1980). The forceps were held in place until the HRP completely dissolved. Seven to 14 days later, the frogs were anesthetized with Finquel ${ }^{\circledR}$ (Ayerst), perfused with $2.5 \%$ glutaraldehyde, and lumbosacral spinal cord was removed and sectioned. Serial cryostat sections were cut at $40 \mu \mathrm{m}$, reacted with the Hanker-Yates substrate for HRP (Hanker et al., 1977) and mounted; motoneurons containing the brown reaction product were counted.

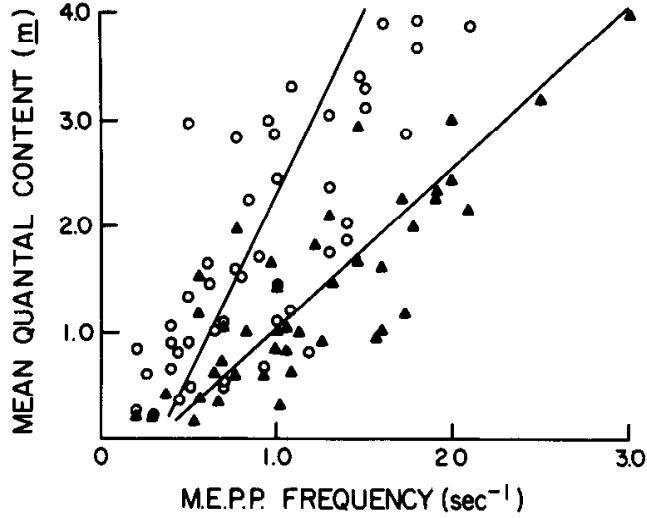

Figure 2. Relationship between mean quantal content $(m)$ and MEPP frequency for sartorius (circles) and e.l.d. (triangles) junctions. Each point represents an individual junction. Representative data from sartorius and e.l.d. junctions whose $m$ value did not exceed 4.0 are shown in order to facilitate comparison (see Results). For both sartorius and e.l.d. muscles, $m$ and MEPP frequency were positively correlated. The correlation coefficient was 0.79 for sartorius ( 47 end-plates in six muscles) and 0.81 for e.l.d. junctions (55 end-plates in six muscles). The slopes of the least-square regression lines were significantly different $(p<0.05 ; t$ test $)$

Cross-sectional area of the HRP-filled motoneurons was determined from camera lucida drawings of cell bodies that contained a clearly defined nucleolus (McHanwell and Biscoe, 1981). The cell body outlines were digitized with the aid of a digital data pad and the cross-sectional area and perimeter measured using a PDP-11/45 computer.

\section{Statistics}

Unless otherwise specified, the data are presented as means \pm SEM. Mean values in Table 1 were compared by Student's (two-tailed) $t$ test and were considered significantly different when $p<0.05$. $n$ refers to the number of animals in a particular experimental group. Values in Table 2 were calculated from the experimental data in Table 1.

\section{Results}

\section{Transmitter release}

\section{Spontaneous release}

The frequency of MEPPs was significantly different in the two muscles. As shown in Table 1, the mean MEPP frequency per end-plate was $1.1 \pm 0.2 \mathrm{sec}^{-1}$ for the sartorius and $0.8 \pm 0.1$ $\mathrm{sec}^{-1}$ for the e.l.d.

The mean MEPP amplitude was significantly larger in e.l.d. than in sartorius muscle fibers $(0.64 \pm 0.08 \mathrm{mV}$, in 22 muscles vs $0.45 \pm 0.05 \mathrm{mV}$, in 22 muscles; $p<0.05$ ). However, MEPP

Table 2. Physiological and morphological properties of nerve terminals and motoneurons innervating frog sartorius and e.l.d. muscles ${ }^{a}$

\begin{tabular}{lrr} 
& Sartorius & E.l.d. \\
Parameter & 217.8 & 101.9 \\
a. Number of end-plates per muscle & 2327.1 & 102.9 \\
b. Number of nerve terminals per muscle & 141.0 & 32.2 \\
c. Number of nerve terminals per motoneuron & 935.3 & 733.2 \\
d. Length of nerve terminal $(\mu \mathrm{m})$ & 3.4 & 1.3 \\
e. Evoked transmitter release $(m$ value) per nerve terminal & 479.4 & 41.9 \\
f. Evoked transmitter release $(m$ value) per motoneuron & 1.0 & 0.8 \\
g. MEPP frequency $\left(\mathrm{sec}^{-1}\right)$ per nerve terminal & 141.0 & 25.8 \\
h. MEPP frequency $\left(\mathrm{sec}^{-1}\right)$ per motoneuron & & \\
\hline
\end{tabular}

${ }^{a}$ Values calculated from the experimental data in Table 1 (see Results). 
amplitude is known to be proportional to muscle fiber input resistance, which was found to be significantly greater, on average, for e.l.d. $(1.1 \pm 0.1 \mathrm{M} \Omega)$ than for sartorius $(0.75 \pm 0.1$ $\mathrm{M} \Omega)$ muscle fibers. Quantal size $(0.58 \mathrm{mV} / \mathrm{M} \Omega$ for e.l.d.; 0.65 $\mathrm{mV} / \mathrm{M} \Omega$ for sartorius), derived by normalizing the MEPP amplitude for differences in muscle fiber input resistance (Katz and Thesleff, 1957), was not significantly different $(p>0.05)$. The similarity in quantal size suggests that the amount of transmitter per quantum and the density of postsynaptic $\mathrm{ACh}$ receptors may be similar in the two muscles.

\section{Evoked release}

Under low $\mathrm{Ca}^{2+}$-high $\mathrm{Mg}^{2+}$ conditions, the $m$ value at sartorius end-plates was approximately 2.8 times greater than that of e.l.d. end-plates (3.6 vs 1.3 , Table $1, \mathrm{i})$. The distribution of $m$ values shown in Figure 1 shows that, at the same ambient $\mathrm{Ca}^{2+} / \mathrm{Mg}^{2+}$ concentrations, junctions with EPPs of large quantal content occur more frequently in the sartorius than in the e.l.d. muscle.

\section{Relationship between spontaneous and evoked release} differs for sartorius and e.l.d. muscles

A positive correlation between $m$ and the MEPP frequency was found in both sartorius and e.l.d. junctions (Fig. 2). For clarity, Figure 2 was constructed from a subset of six pairs of muscles in which the largest individual $m$ did not exceed 4.0; the relationship between $m$ and MEPP frequency was similar when junctions having larger $m$ values were included. The slope of $m$ vs MEPP frequency for the sartorius junctions was approximately twice that of e.l.d. junctions, and this difference was statistically significant.

\section{Spontaneous and evoked release differ in their dependence on nerve terminal length}

Transmitter release from amphibian motor nerve terminals is believed to take place at regularly spaced "active zones" that occur in register with the junctional folds of the end-plate (Heuser and Reese, 1973). Based on the finding that $m$ and MEPP frequency at the frog neuromuscular junction are proportional to nerve terminal size, Kuno et al. (1971) suggested that this dependency may result from increased numbers of active zones with increasing terminal length. Thus, the observed differences in transmitter release between sartorius and e.l.d. junctions may simply reflect differences in total length of the nerve terminal.

In the present study, the mean total length of nerve terminals in each of the two muscles was determined from randomly selected, superficial fibers stained both for AChE activity (Karnovsky and Roots, 1964) and nerve terminals (Letinsky and DeCino, 1980). Presumably, these samples were representative of those from which electrophysiological data were collected (see above). At a particular neuromuscular junction, the nerve terminal and end-plate were found to be coextensive along at least $97 \%$ of their total length. Thus, we consider the length of the end-plate and nerve terminal within a given junction to be essentially equivalent, a conclusion that is consistent with previous studies (Letinsky and DeCino, 1980; Letinsky et al., 1976; Wernig et al., 1980).

As shown in Table 1, h, mean end-plate length and, therefore, mean total length of the nerve terminal per end-plate were significantly greater in sartorius than in the e.l.d. muscle (1002.6 \pm $113.9 \mu \mathrm{m} ; 205$ junctions in 14 muscles vs $740.4 \pm 82.1 \mu \mathrm{m}$; 169 junctions in 13 muscles). This difference in total nerve terminal length (1.4-fold) was similar to the difference in mean MEPP frequency per end-plate (1.4-fold), suggesting that the greater MEPP frequency in sartorius junctions may be accounted for by the greater overall length of sartorius nerve terminals. In fact, when the mean MEPP frequency was divided by mean end-plate length (in 14 sartorius and 13 e.l.d. muscles for which both sets of data were available from the same animal), the

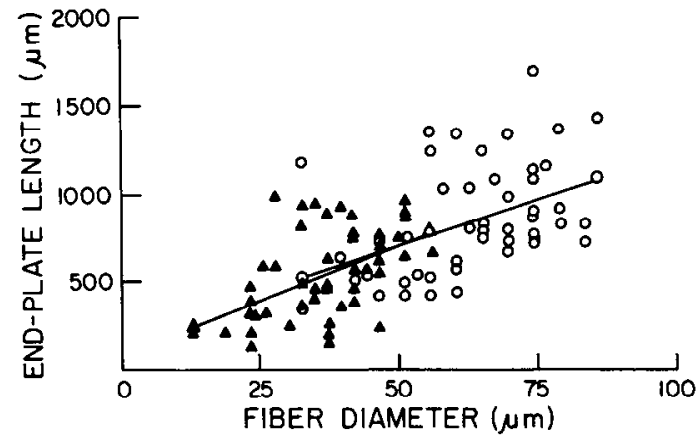

Figure 3. Relationship between end-plate length and muscle fiber diameter in sartorius (circles) and e.l.d. (triangles) fibers from a pair of muscles taken from the same animal. The slopes of the least-square regression lines were not significantly different $(p>0.05 ; t$ test). The correlation coefficients were 0.46 for sartorius and 0.58 for e.l.d. fibers.

calculated rate of spontaneous discharge of transmitter per unit length of nerve terminal was not significantly different between e.l.d. and sartorius terminals (MEPP frequency $=1.1 \perp 0.3$ $\mathrm{sec}^{-1} \cdot 1000 \mu \mathrm{m}^{-1}$ for sartorius vs $1.2 \pm 0.2 \mathrm{sec}^{-1} \cdot 1000 \mu \mathrm{m}^{-1}$ for e.l.d.; Table 1, 1). Thus, comparable lengths of nerve terminal in the two muscles appear to have equivalent rates of spontaneous transmitter release.

In contrast, when the average $m$ value was normalized for differences in end-plate length, $m$ per unit length was significantly greater at sartorius than at e.l.d. junctions (Table $1, \mathrm{j}$ ). Clearly, under our experimental conditions, intrinsic physiological differences existed between the two types of nerve terminals. In response to a single stimulus, sartorius terminals released $3.7 \pm 1.0$ quanta/ $1000 \mu \mathrm{m}$ of terminal, whereas e.l.d. terminals released an average of $1.7 \pm 0.3$ quanta/ $1000 \mu \mathrm{m}$ of terminal. Our results show that the 2.8 -fold greater average $m$ value at sartorius junctions cannot be explained on the basis of differences in nerve terminal length. Rather, it appears that this difference may be related to intrinsic differences between release per unit length of nerve terminal in the two muscles.

\section{Possible causes for the disparity in $\mathrm{m}$ per unit length of nerve terminal in sartorius and e.l.d. muscles}

\section{Relationship between fiber diameter and nerve terminal length}

It is widely accepted that among fibers in a given muscle, release and end-plate length are positively correlated with muscle fiber diameter (see review, Grinnell and Herrera, 1981). Within this overall trend, however, it has been shown that for fibers of comparable diameter, there may be an inverse relationship between the $m$ value per unit length and total terminal length (Nudell and Grinnell, 1982). Thus, we examined whether the greater $m$ value per unit length in the sartorius muscle might reflect compensation for a less steep relationship between nerve terminal length and fiber diameter in sartorius than in e.l.d. muscles, so that the safety factor at end-plates on similar diameter muscle fibers was equivalent.

The mean diameter of sartorius fibers $(58.0 \pm 4.0 \mu \mathrm{m})$ was found to be significantly greater (Table $1, b)$ than that of fibers in the e.1.d. muscle $(39.4 \pm 3.9 \mu \mathrm{m})$, an observation compatible with the observed differences in muscle fiber input resistance (Table $1, c)$. Mean end-plate length was significantly greater in the sartorius than in the e.l.d. muscle (see above). However, as shown in Figure 3, the slope of the relationship between endplate length and fiber diameter was similar in sartorius and e.l.d. muscles. Thus, the observed differences in transmitter release cannot be attributed to a compensation for a different relationship between muscle fiber diameter and length of the end-plate. 
Table 3. Quantal contents ( $m$ values) of sartorius $[m($ sart $)]$ and e.l.d. [m(e.l.d.)] end-plates in muscles bathed with solutions with different $\mathrm{Ca}^{2+}$ and $\mathrm{Mg}^{2+}$ concentrations ${ }^{a}$

\begin{tabular}{|c|c|c|c|c|}
\hline \multirow{2}{*}{\multicolumn{2}{|c|}{$\begin{array}{l}\text { Divalent cation } \\
\text { concentration }(\mathrm{mM})\end{array}$}} & \multicolumn{3}{|l|}{$m$ Value } \\
\hline & & \multirow[b]{2}{*}{$m$ (sart) } & \multirow[b]{2}{*}{$m$ (e.l.d.) } & \multirow{2}{*}{$\begin{array}{l}m \text { (sart)/ } \\
m \text { (c.l.d.) }\end{array}$} \\
\hline $\mathrm{Ca}^{2+}$ & $\mathbf{M g}^{2+}$ & & & \\
\hline 0.6 & 10.0 & $\begin{array}{r}3.6 \pm 0.7 \\
(n=22)\end{array}$ & $\begin{array}{r}1.3 \pm 0.2 \\
(n=22)\end{array}$ & 2.8 \\
\hline 0.7 & 9.0 & $\begin{array}{c}21.1 \pm 8.4 \\
\quad(n=4)\end{array}$ & $\begin{array}{c}8.1 \pm 3.0 \\
(n=4)\end{array}$ & 2.6 \\
\hline
\end{tabular}

$n$ refers to number of animals in the experimental group.

${ }^{a}$ Values are means \pm SEM.

\section{Incomplete action potential invasion of the nerve terminal}

One physiological process that might explain the difference in $m$ per end-plate (and, therefore, in $m$ per unit length of terminal) is failure of action potential conduction into terminal branches. If failure of invasion occurred with greater incidence in e.l.d. terminals, the difference in $m$ value between e.l.d. and sartorius junctions might be considerably less than that predicted from the observed differences in terminal length. Because MEPP frequency does not depend on action potential invasion, one would expect the ratio of $m$ /MEPP frequency to differ between the two muscles, as we found to be the case (Fig. 2). To test for invasion failure, we examined the responses to stimulation in e.l.d. endplates with $m$ values of less than one. Conduction failure, if present in this group of low quantal content junctions, should be readily evidenced by fewer EPPs composed of one, two, or three quanta than predicted from Poisson's theorem and the observed number of failures. In all cases, the number of EPPs with single, double, or higher-multiple quantal contents agreed well with predictions from the observed number of failures. Moreover, at each junction, there was good agreement between estimates of quantal content calculated by the three different procedures (see Methods; Martin, 1966). Thus, it seems unlikely that the difference in evoked release from e.l.d. and sartorius terminals can be attributed to intermittent conduction failure.

\section{Dependence of transmitter release on extracellular calcium concentration}

We also considered the possibility that the dependence of quantal content on $\mathrm{Ca}^{2+}$ or $\mathrm{Mg}^{2+}$ concentration might differ between terminals in the two muscles. To test the $\mathrm{Ca}^{2+}$ and $\mathrm{Mg}^{2+}$ sensitivity of the terminals, we compared the $m$ value of sartorius and e.l.d. junctions in bathing solutions of differing divalent cation composition (Table 3). With ambient $\mathrm{Ca}^{2+}$ and $\mathrm{Mg}^{2+}$ concentrations of 0.6 and $10.0 \mathrm{~mm}$, respectively, the average $m$ of sartorius terminals was about 2.8 times that of e.l.d. terminals (Tables $1, \mathrm{i}$, and 3 ). When the $\mathrm{Ca}^{2+}$ concentration was elevated to $0.7 \mathrm{~mm}$ and the $\mathrm{Mg}^{2+}$ concentration was reduced to $9.0 \mathrm{~mm}$, the absolute values of quantal content per end-plate were increased substantially in both muscles (Table 3). The ratio of $m$ values between sartorius and e.l.d. junctions $[m$ (sart) $/ m$ (e.l.d.) in Table 3l, however, was similar (2.6 vs 2.8 ). Such results are consistent with the idea that the slope of the relationship between $m$ and external $\mathrm{Ca}^{2+}$ and $\mathrm{Mg}^{2+}$ is similar in sartorius and e.l.d. junctions. Our results are in agreement with those of Grinnell and Herrera (1980b), who found that the slope of the relation between $m$ and external $\mathrm{Ca}^{2+}$ concentration was the same in frog cutaneous pectoris and sartorius muscles even though the average $m$ value per unit length of nerve terminal differed by 3 -fold.

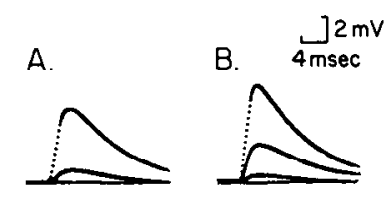

Figure 4. Focal polyneuronal innervation in frog sartorius muscle fibers. The intracellularly recorded EPP shows two $(A)$ or, less often, three $(B)$ components, each recruited at a sharply defined threshold, with graded stimulation of the muscle nerve. The muscle was paralyzed with $d$-tubocurare, $3 \times 10^{-6} \mathrm{M}$.

\section{Number of nerve terminals per motoneuron}

Grinnell and colleagues $(1980,1980 \mathrm{a}, \mathrm{b}, 1983)$ have proposed that quantal content per unit length of nerve terminal is related to the number of nerve terminals maintained by a motoneuron. To further examine this relationship, we gathered the following data, which were then used to estimate the number of nerve terminals supported, on average, by a motoneuron: (1) the mean number of motoneurons innervating each muscle; (2) the mean total number of end-plates in each muscle; and (3) the incidence of polyneuronal innervation and the average number of polyneuronal inputs per junction in each muscle.

The numbers of sartorius and e.l.d. motoneurons were estimated by counting the labeled anterior horn cells in the ipsilateral spinal cord (see Methods). The mean number of motoneurons supplying the sartorius muscle was 16.5 (Table 1, f), a value that agrees well with previous estimates of $10-15$, based on the number of increments in twitch tension observed with graded stimulation of the sartorius nerve (Grinnell and Rheuben, 1979; Herrera and Grinnell, 1980; Luff and Proske, 1976). HRP application to the e.l.d. nerve resulted in a mean of 3.2 labeled motoneurons (Table 1, f). Thus, the e.l.d. muscle is innervated by considerably fewer motoneurons than is the sartorius muscle.

The total number of end-plates per muscle can be calculated from the number of fibers per muscle and average number of end-plates per fiber. The sartorius muscle contains about 10 times more extrafusal fibers, on average, than does the e.l.d. muscle $(804.0 \pm 27.7$ vs $78.4 \pm 2.8$; Table 1 , a) .

In agreement with earlier work (Weakly, 1980), the number of end-plates per muscle fiber, as determined from AChE-stained material, was different in the two muscles (Tables 1, e). The number of end-plates per sartorius fibcr ranged from 2 to 5 , with a mean of 2.7 ; in contrast, e.l.d. muscle fibers each had one or two end-plates, with a mean of 1.3 per fiber. Thus, there are, on average, 2170.8 end-plates in the sartorius and 101.9 in the e.l.d. muscles (Table 2, a). In each muscle, the total number of nerve terminals (Table 2, b) exceeds the number of end-plates by a small amount because some end-plates are innervated by two or more axons. Such focal polyneuronal innervation was revealed by intracellular recording from lightly curarized muscles (Fig. 4). With graded stimulation some EPPs could be broken into 2 (Fig. $4 A$ ) or occasionally 3 (Fig. $4 B$ ) components, which usually showed similar rise time, duration and latency. Such end-plates were most often supplied by two axons; endplates with three axons were encountered in only 1.4 and $4.0 \%$ of polyneuronally innervated sartorius and e.l.d. end-plates, respectively. The overall incidence of focal polyneuronal innervation was low in both muscles $(7.1 \%$ in the sartorius and $1.0 \%$ in the e.l.d.; Table 1, d).

The number of end-plates per muscle (Table 2, a), along with the incidence of doubly and triply innervated end-plates can be used to estimate the total number of nerve terminals per muscle, which was calculated to be 2327.1 in sartorius and 102.9 in the e.l.d. (Table 2, b). If it is assumed that the nerve terminals are 
distributed equally among the observed number of HRP-labeled motoneurons, our data suggest that the number of terminals maintained by a "typical" sartorius motoneuron (141.0) is more than $4 \times$ greater, on average, than that maintained by an e.l.d. motoneuron $(32.2$; Table $2, \mathrm{c})$. Thus, a given sartorius motoneuron, on average, releases more transmitter per length of nerve terminal on stimulation and supports more nerve terminals than an e.l.d. motoneuron. Evoked release per unit length of nerve terminal, therefore, is not inversely related to the number of nerve terminals maintained in either sartorius or e.1.d. motoneurons.

\section{Other differences between sartorius and e.l.d. motoneurons}

Little is known about the factors that determine characteristic motoneuron properties. It is known that larger motoneurons conduct action potentials more rapidly along their axons (see review, Schwindt, 1976) and are associated with larger motor units (Luff and Proske 1976; Ridge and Thomson, 1980). We have examined whether sartorius and e.l.d. motoneurons differ in (1) average cross-sectional area of the motoneuron cell body, (2) total release per motoneuron, and (3) total aggregate length of synaptic contact per motoneuron.

\section{Cell body size}

Cross-sectional area was determined from tracings of HRPlabeled motoneuron profiles containing a clearly defined nucleolus (see Methods). Although considerable overlap in the areas of individual motoneurons was evident (Fig. 5), the mean cross-sectional area of sartorius motoneurons $\left(1601.7 \mu \mathrm{m}^{2}\right)$ was significantly greater (Table $1, \mathrm{~g}$ ) than that of e.l.d. motoneurons $\left(1113.3 . \mu \mathrm{m}^{2}\right)$. Thus, sartorius motoneurons, which supported the greater number of nerve terminals (see above), also had larger cell bodies than e.l.d. motoneurons.

\section{Transmitter release per motoneuron}

The estimated total MEPP frequency per sartorius motoneuron (the product of frequency per terminal and the number of terminals per motoneuron) was $141.0 \mathrm{sec}^{-1}$, compared with 25.8 $\mathrm{sec}^{-1}$ for e.l.d. motoneurons (Table $2, \mathrm{~h}$ ). The resting discharge of transmitter in the form of spontaneous MEPPs, therefore, was more than $5 \times$ larger for sartorius than for e.l.d. motoneurons.

Total evoked release (total $m$ value) was also markedly larger from sartorius than from e.l.d. motoneurons. On average, sartorius motoneurons released about $11 \times$ more quanta per impulse than e.l.d. motoneurons (479.4 vs 41.9 quanta; Table 2, f). Thus, sartorius motoneurons released more transmitter both from individual terminals (Table $2, \mathrm{e}, \mathrm{g}$ ) and from all their terminals together (Table $2, \mathrm{f}, \mathrm{h}$ ), than did e.l.d. motoneurons.

\section{Total length of synaptic contact per motoneurons}

Because more than one nerve terminal may occupy an end-plate (see above), the mean end-plate length shown in Table $1, \mathrm{~h}$ is not necessarily indicative of the length of individual nerve terminals. Nevertheless, the length of sartorius and e.l.d. terminals can be estimated (Table 2 , d) by multiplying the total terminal length per end-plate (Table $1, h$ ) by the total numbers of endplates per muscle and dividing this product by the number of nerve terminals per muscle (Table $2, a, b$ ). On this basis, the mean length of individual sartorius nerve terminals was determined to be approximately $935 \mu \mathrm{m}$, whereas the mean length of e.l.d. terminals was approximately $733 \mu \mathrm{m}$. Thus, the length of individual nerve terminals, as well as the total length of nerve terminal per end-plate (see above), is greater in the sartorius than in the e.l.d. muscle.

Finally, if one compares the mean aggregate length of all terminals maintained by a sartorius or e.l.d. motoneuron (cal-

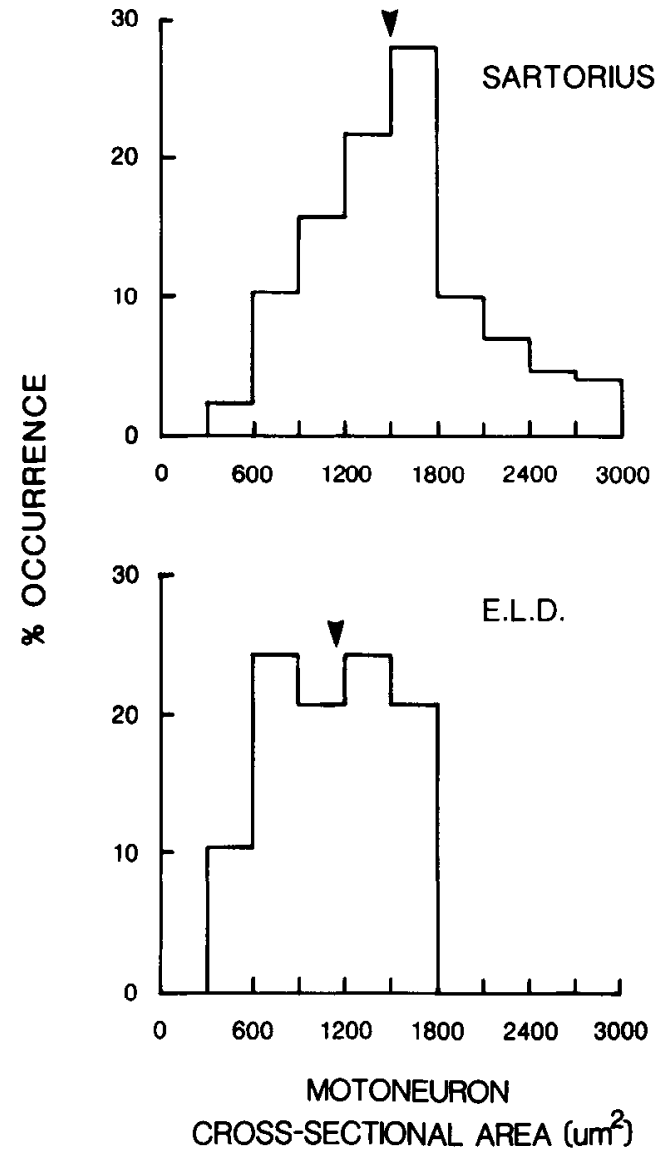

Figure 5. Histograms showing distribution of cross-sectional area of motoneurons innervating sartorius and e.l.d. muscles. Arrows indicate means: sartorius, $1601.7 \pm 49.8$ (129 motoneurons from 10 animals); e.l.d., $1113.3 \pm 67.9$ (29 motoneurons from 10 animals). Mean crosssectional areas for motoneurons innervating the two muscles were significantly different by $t$ test $(p<0.001)$.

culated by dividing the total end-plate length per muscle by the number of motoneurons), another striking difference is noted. The combined length of nerve terminals supported by a "typical" sartorius motoneuron $(131.9 \mathrm{~mm})$ is approximately $5.6 \times$ larger than for an e.l.d. motoneuron $(23.6 \mathrm{~mm})$.

\section{Discussion}

Tables 1 and 2 summarize the differences in motoneuron and muscle properties between the sartorius and e.l.d. muscles. Of particular interest was the observed 2.8-fold difference in mean quantal content $(m)$ per end-plate between sartorius and e.l.d. muscles. Even after the average $m$ for each muscle was normalized for length, the $m$ value per unit length of end-plate of sartorius terminals was more than twice that of e.1.d. terminals. Nerve terminal length, therefore, only partially accounts for the difference in evoked transmitter release.

From data in this and previously published work, the impulsedependent release of transmitter $(m)$ per unit length of nerve terminal varies substantially among different frog muscles. The $m$ value per unit length appears largest in the cutaneous pectoris (Grinnell and Herrera, 1980b), being about $3 \times$ that of sartorius and $6 \times$ greater than for terminals of the e.l.d. muscle (see Results).

We have expressed the differences in release properties of sartorius and e.l.d. terminals in terms of $m$ per unit length. It should be pointed out that these values are averages and are not necessarily intended to imply that release is uniform along 
the entire length of a terminal. In fact, evidence of variability in the probability of evoked release along frog terminals has been presented (Bennett and Lavidis, 1979, 1982; DeCino, 1981; but cf. D'Alonzo and Grinnell, 1982). Even if release is not uniform, however, the greater average release from sartorius terminals indicates that their release sites are more effective or greater in number, irrespective of their spatial distribution, than release sites in e.l.d. muscles.

The basis for differences in $m$ per unit length of nerve terminal in different muscles remains to be determined. We find that the difference in $m$ per unit length of nerve terminal at sartorius from e.l.d. terminals cannot be explained by different $\mathrm{Ca}^{2+}$ and $\mathrm{Mg}^{2+}$ sensitivities (Table 3) or by intermittent failure of conduction in the terminals of the e.l.d. muscles. A similar conclusion has been reached by Grinnell and Herrera (1980b) from their comparison of sartorius and cutaneous pectoris release properties.

Recently, Mallart (1984) has shown that the density of sodium channels is very low at the most distal regions of the nerve terminal in the frog. This finding raises the possibility that the action potential does not fully invade terminal branches of frog motor endings. It is possible that the length of nerve terminal invaded by an action potential is greater in sartorius than in e.l.d. terminals and that differences in the degree of invasion may underlie the observed differences in $m$ per unit length of terminal.

Another possible explanation for the different $m$ values is that competitive interactions between terminals at separate end-plates on the same muscle fiber may result in a lower $m$ value than at junctions on muscle fibers innervated at a single site (e.g., see Grinnell et al., 1977, 1979; Haimann et al., 1981; Mallart et al., 1980). The present experiments show that a reciprocal relation between $m$ and the mean number of end-plates per fiber is not invariably present among different muscles. Despite the greater average number of end-plates on sartorius fibers, the $m$ value at sartorius end-plates was found to be distinctly greater than at e.l.d. end-plates (Table 1, h). Thus, although the number of end-plates per fiber may be one determinant of synaptic efficacy, our data suggest that other factors must also be considered.

In addition to physiological processes, there are a number of presynaptic morphological differences, including (1) width of the nerve terminal, (2) spacing of active zones, and (3) density of synaptic vesicles, which might explain the observed differences in transmitter release between sartorius and e.l.d. nerve terminals. Our measurements of active zone spacing and nerve terminal width at the LM level have revealed no significant differences between sartorius and e.l.d. preparations. Similarly, Grinnell and Herrera (1980b) found no morphological correlates, such as (1) spacing of active zones, (2) width of synaptic contact, (3) number of presynaptic vesicles, and (4) number of mitochondria per cross-sectional area of terminals, that could explain the greater release from cutaneous pectoris than from sartorius nerve terminals. Additional studies using EM and freeze-fracture techniques are required to further investigate the possible morphological differences between sartorius and e.l.d. terminals.

We have shown that sartorius motoneurons have more terminals and release greater amounts of transmitter per terminal, on average, than do e.l.d. motoneurons. In contrast, Grinnell and Herrera (1980b) found that cutaneous pectoris motoneurons, which maintained fewer terminals, released more transmitter from their terminals than did sartorius motoneurons. Thus, as was true for $m$ per unit length (see above), $m$ per terminal appears to depend on factors other than, or in addition to, the number of terminals maintained by a motoneuron.

Wc have found MEPP frequency per unit length of nerve terminal and per end-plate (Table 1) to be similar in the sartorius and e.l.d. muscles. Our data also show that the slope of the relationship between MEPP frequency and end-plate length is similar for fibers within the same muscle and from the two muscles (Fig. 3). These similarities raise the possibility that common mechanisms may be acting between nerve and muscle to regulate transmitter release and nerve terminal length in sartorius and e.l.d. muscles.

Our results demonstrate that, for the observed difference in end-plate length between the two muscles, the difference in $m$ was proportionately greater than MEPP frequency (Fig. 2). A dissociation between MEPP frequency and $m$ has also been noted during development and regeneration (see review, DeCino, 1981; Dennis, 1981; Ding, 1982). In addition, the MEPP frequency and $m$ value at adult end-plates depend differently on the external calcium concentration and may be altered differentially after experimental manipulation (Ceccarelli and Hurlbut, 1980; Ceccarelli et al., 1979; Colmeus et al., 1982; Dennis, 1981; Dennis and Miledi, 1971; Hubbard, 1973; Mellow et al., 1982, Molgo and Thesleff, 1982). Together, these observations suggest that spontaneous and evoked release are mediated by separate processes and regulated by different mechanisms.

We have asked whether the length of individual terminals might be less for sartorius motoneurons, which maintained the greater number of terminals, than for e.l.d. motoneurons. Surprisingly, individual sartorius terminals $(935 \mu \mathrm{m})$ were found to be longer, not shorter, on average, than e.l.d. terminals (733 $\mu \mathrm{m})$. Moreover, a "typical" sartorius motoneuron was found to support a minimum of 5-6 $\times$ greater aggregate synaptic contact length than an average e.l.d. motoneuron (132 vs $24 \mathrm{~mm}$ ). Thus, in addition to maintaining greater numbers of terminals, sartorius motoneurons also possess, on average, terminals that are longer, both individually and in their totality, than those of e.l.d. motoneurons. Therefore, from examination of sartorius and e.1.d. motoneurons, we find no evidence that motoneurons with larger numbers of terminals attempt to conserve synaptic machinery by reducing their total terminal length.

It should be emphasized that the observed lack of correlation between number of terminals and individual terminal length among motoneurons innervating different muscles does not exclude the possibility that such a relation is present among the motoneurons supplying any one muscle. Among homonymous motoneurons, there may be an optimum ratio between overall length and number of terminals, but this ratio may differ from one pool of motoneurons to another. Additional experiments are needed to test this point.

The present study has shown that the larger-diameter sartorius motoneurons maintain greater numbers of nerve terminals and total length of synaptic contact with their target muscle and release more transmitter per motoneuron than the smaller-diameter e.l.d. motoneurons. We have calculated mean e.l.d. motoneuron values for these parameters based on our finding that 3.2 motoneurons (Table 1, f) innervate the e.l.d. muscle. This number of motoneurons is less than might be expected from previous anatomical studies (Gray, 1957; Katz, 1949), which suggested that six motor axons supplied the extrafusal fibers of the e.l.d. muscle. It is unclear whether our results represent a true discrepancy with earlier work or whether, for unknown reasons, some e.l.d. motoneurons were not labeled in the present experiments. In this regard, it is noteworthy that both Katz (1949) and Gray (1957) commented on the presence in some animals of anomalous branches of the e.l.d. nerve that became evident only with extensive dissection. In our HRP experiments, the initial dissection was kept to a minimum in order to avoid damage to the surrounding musculature and possible nonspecific labeling of motoneurons. It is possible that some e.l.d. axons did not reccive HRP; if truc, our mcan valuc of 3.2 c.l.d. motoneurons may be regarded as a minimum. The calculated val- 
ues per e.l.d. motoneuron, therefore, represent maxima. Thus, the differences observed between sartorius and e.l.d. motoneurons may be even greater than those shown in Table 2 .

Finally, we do not have an explanation for the differences in transmitter release per unit length of nerve terminal in the two muscles. However, our findings that in both the sartorius and e.l.d. muscles, positive correlations were present between (1) nerve terminal length and muscle fiber diameter, (2) transmitter release and end-plate length, and (3) transmitter release per endplate, release per motoneuron, and the number of nerve terminals supported by a motoneuron (and consequently the number of end-plate sites contacted by a given motoneuron) raise two testable hypotheses. First, these findings raise the possibility that retrograde signals from muscle may influence the release properties of the motoneuron. Alternatively, these observations may represent inherent, fixed properties of motoneurons (Grinnell and Trussell, 1983). A subsequent paper will present the results of cross-innervation experiments, which suggest that the properties of frog motoneurons depend, at least in part, on their particular target muscle.

\section{References}

Angaut-Petit, D., and A. Mallart (1979) Dual innervation of end-plate sites and its consequences for neuromuscular transmission in muscles of adult Xenopus laevis. J. Physiol. (Lond.) 284: 203-218.

Bennett, M. R., and N. A. Lavidis (1979) The effect of calcium ions on the secretion of quanta evoked by an impulse at nerve terminal release sites. J. Gen. Physiol. 74: 429-456.

Bennett, M. R., and N. A. Lavidis (1982) Variation in quantal secretion at different release sites along developing and mature motor terminal branches. Dev. Brain Res.. 5: 1-9.

Ceccarelli, B., and W. P. Hurlbut (1980) Vesicle hypothesis of release of quanta of acetylcholine. Physiol. Rev. 60: 396-441.

Ceccarelli, B., F. Grohovaz, and W. P. Hurlbut (1979) Freeze-fracture studies of frog neuromuscular junctions during intense release of neurotransmitter. II. Effects of electrical stimulation and high potassium. J. Cell Biol. 81: 178-192.

Colmeus, C., S. Gomez, J. Molgo, and S. Thesleff (1982) Discrepancies between spontaneous and evoked synaptic potentials at normal, regenerating and botulinum toxin poisoned mammalian neuromuscular junctions. Proc. R. Soc. London [Biol.] 215: 63-74.

D'Alonzon, A. J., and A. D. Grinnell (1982) Uniformity of transmitter release along the length of frog motor nerve terminals. Soc. Neurosci. Abstr. 8: 493 .

DeCino, P. (1981) Transmitter release properties along regenerated nerve processes at the frog neuromuscular junction. $J$. Neurosci. 1: $308-317$

Del Castillo, J., and B. Katz (1954) Quantal components of the endplate potential. J. Physiol. (Lond.) 124: 560-573.

Dennis, M. J. (1981) Development of the neuromuscular junction: Inductive interactions between cells. Annu. Rev. Neurosci. 4: 308317.

Dennis, M. J., and R. Miledi (1971) Lack of correspondence between the amplitudes of spontaneous potentials and unit potentials evoked by nerve impulses at regenerating neuromuscular junctions. Nature 232: $126-128$.

Ding, R. (1982) Lack of correlation between physiological and morphological features of regenerating frog neuromuscular junctions. Brain Res. 253: 47-55.

Farel, P. B., and S. E. Bemelmans (1980) Retrograde labeling of migration spinal motoneurons in bullfrog larvae. Neurosci. Lett. 18: 133-136.

Gray, E. G. (1957) Spindle and extrafusal innervation of frog muscle. Proc. R. Soc. Lond. [Biol.] 146: 416-430.

Gray, E. G. (1958) The structure of fast and slow muscle fibres in frog. J. Anat. 92: 559-562.

Grinnell, A. D., and A. A. Herrera (1980a) Synaptic efficacy depends on motor unit size in normal frog neuromuscular junctions. Soc. Neurosci. Abstr. 6: 571.

Grinnell, A. D., and A. A. Herrera (1980b) Physiological regulation of synaptic effectiveness at frog neuromuscular junctions. J. Physiol. (Lond.) 307: 301-317.
Grinnell, A. D., and A. A. Herrera (1981) Specificity and plasticity of neuromuscular connections: Long-term regulation of motoneuron function. Prog. Neurobiol. 17: 203-282.

Grinnell, A. D., and M. B. Rheuben (1979) The physiology, pharmacology and trophic effectiveness of synapses formed by autonomic preganglionic nerve on frog skeletal muscle. J. Physiol. (Lond.) 289: $219-240$.

Grinnell, A. D., and L. O. Trussell (1983) Synaptic strength as a function of motor unit size in the normal frog sartorius. J. Physiol. (Lond.) 338: 221-241.

Grinnell, A. D., M. B. Rheuben, and M. S. Letinsky (1977) Mutual repression of synaptic efficacy by pairs of foreign nerves innervating frog skeletal muscle. Nature $265: 368-370$.

Grinnell, A. D., M. S. Letinsky, and M. B. Rheuben (1979) Competitive interactions between foreign nerves innervating frog skeletal muscle. Nature 265: 368-370.

Haimann, C., A. Mallart, J. Tomas I Ferre, and N. F. Zilber-Gachelin (1981) Interaction between motor axons from two different nerves reinnervating the pectoral muscle of Xenopus laevis. J. Physiol. (Lond.) 310: 257-272.

Hanker, J. A., P. E. Yates, C. E. Metz, and A. Rustioni (1977) A new specific, sensitive and noncarcinogenic reagent for the demonstration of horseradish peroxidase. Histochem. J. 9: 789-792.

Herrera, A. A., and A. D. Grinnell (1980) Transmitter release from frog motor nerve terminals depends on motor unit size. Nature 287. $649-651$.

Heuser, J. E., and T. S. Reese (1973) Evidence for recycling of synaptic vesicle membrane during transmitter release at the frog neuromuscular junction. J. Cell Biol. 57: 315-344.

Hubbard, J. I. (1973) Microphysiology of vertebrate neuromuscular transmission. Physiol. Rev. 53: 674-723.

Karnovsky, M. J., and L. Roots (1964) A 'direct-coloring' thiocholine method for cholinesterases. J. Histochem. Cytochem. 12: 219-221.

Katz, B. (1949) The efferent regulation of the muscle spindle in the frog. J. Exp. Biol. 26: 201-217.

Katz, B., and S. Thesleff (1957) On the factors which determine the amplitude of the miniature end-plate potential. J. Physiol. (Lond.) 137: 267-278

Kuffler, S. W., and E. M. Vaughn Williams (1953) Small-nerve junctional potentials. The distribution of small motor nerves to frog skeletal muscle, and the membrane characteristics of the fibres they innervate. J. Physiol. (Lond.) 121: 289-317.

Kuno, M., S. A. Turkanis, and J. N. Weakly (1971) Correlation between nerve terminal size and transmitter release at the neuromuscular junction of the frog. J. Physiol. (Lond.) 213: 545-556.

Letinsky, M. S., and P. DeCino (1980) Histological staining of preand post-synaptic components of amphibian neuromuscular junctions. J. Neurocytol. 9: 305-320.

Letinsky, M. S., K. H. Fishbeck, and U. J. McMahan (1976) Precision of reinnervation of original postsynaptic sites in frog muscle after nerve crush. J. Neurocytol. 5: 691-718.

Luff, A. R., and U. Proske (1976) Properties of motor units of the frog sartorius muscle. J. Physiol. (Lond.) 258: 673-685.

Mallart, A. (1984) Presynaptic currents in frog motor endings. Pfluegers Arch. 400: 8-13.

Mallart, A., D. Angaut-Petit, N. F. Zilber-Zachelin, J. Tomas I Ferre, and C. Haimann (1980) Synaptic efficacy and turnover of endings in pauciinnervated muscle fibres of Xenopus laevis. In Ontogenesis and Functional Mechanisms of Peripheral Synapses, INSERM Symp. 13, J. Taxi, ed., pp. 213-223, Elsevier/North-Holland, Amsterdam.

Martin, A. R. (1966) Quantal nature of synaptic transmission. Physiol. Rev, 46: 51-66.

McHanwell, S., and Biscoe, T. J. (1981). The sizes of motoneurons supplying hindlimb muscles in the mouse. Proc. R. Soc. Lond. [Biol.] 213: 201-216.

McLachlan, E. M., and A. R. Martin (1981) Non-linear summation of end-plate potentials in the frog and mouse. J. Physiol. (Lond.) 311: 307-324.

Mellow, A. M., D. B. Perry, and E. M. Silinsky (1982) Effects of calcium and strontium in the process of acetylcholine release from motor nerve endings. J. Physiol. (Lond.) 328: 547-562.

Molgo, J., and S. Thesleff (1982) 4-Aminoquinoline-induced 'giant' miniature end-plate potentials at mammalian neuromuscular junctions. Proc. R. Soc. Lond. [Biol.] 214: 229-247.

Nudell, B. M., and A. D. Grinnell (1982) Inverse relationship between 
transmitter release and terminal length in synapses on frog muscle fibers of uniform input resistance. J. Neurosci. 2: 216-224.

Nudell, B. M., and A. D. Grinnell (1983) Regulation of synaptic position, size and strength in anuran skeletal muscle. J. Neurosci. 3: $161-176$.

Pockett, S., and J. R. Slack (1982) Pruning of axonal trees results in increased efficacy of surviving nerve terminals. Brain Res. 243: 350353.

Redfern, P. A. (1970) Neuromuscular transmission in new-born rats. J. Physiol. (Lond.) 209: 701-709.

Ridge, R. M. A. P., and A. M. Thomson (1980) Properties of motor units in a small foot muscle of Xenopus laevis. J. Physiol. (Lond.) 306: 17-27.

Schwindt, P. C. (1976) Electrical properties of spinal motoneurons.
In Frog Neurobiology, R. Llinas and W. Precht, eds., pp. 750-764, Springer-Verlag, New York.

Slack, J. R., and W. G. Hopkins (1982) Neuromuscular transmission at terminals of sprouted mammalian motor neurones. Brain Res. 237 : $121-135$

Weakly, J. N. (1978) Similarities in synaptic efficacy along multiplyinnervated twitch muscle fibers of the frog: A possible muscle-tomotoneuron interaction. Brain Res. 158: 235-239.

Weakly, J. N. (1980) The number of end-plates is independent of the physical parameters of twitch fibers in amphibian muscles. Brain Res. 197: 271-273.

Wernig, A., M. Pechot-Dechavassine, and H. Stover (1980) Sprouting and regression of the frog neuromuscular junction in normal conditions and after paralysis with curare. J. Neurocytol. 9: 277-303. 